\title{
EVENTOS ADVERSOS GRAVES EM PACIENTES CIRÚRGICOS: OCORRÊNCIA E DESFECHO
}

\author{
Serious adverse events in surgical patients: occurrences and outcomes
}

Eventos adversos graves en pacientes quirúrgicos: ocurrencia y desenlace

Isabella Sanches de Araújo', Rachel de Carvalho*

RESUMO: Objetivo: Identificar a ocorrência de eventos adversos graves (EAG) em pacientes cirúrgicos e seus possíveis desfechos. Método: Estudo retrospectivo, quantitativo, realizado pela análise de prontuários e banco de dados de pacientes no perioperatório, que sofreram EAG em 2016, em um hospital privado de São Paulo. Resultados: Ocorreram 19 EAG, com predominância de pacientes do sexo feminino, entre 40 e 49 anos, internados por patologias do sistema gastroenterológico. As ocorrências mais incidentes foram: lesão de órgãos digestórios, choque hemorrágico e lesão vascular. Quanto aos desfechos, os pacientes foram encaminhados à unidade de terapia intensiva, clínica médico-cirúrgica e hemodinâmica; dois pacientes evoluíram a óbito. Conclusão: Os profissionais da equipe de enfermagem devem estar atentos aos fatores que podem contribuir para a ocorrência de EAG e orientados em relação à notificação, a fim de aperfeiçoar a segurança e a qualidade da assistência prestada aos pacientes cirúrgicos.

Palavras-chave: Enfermagem perioperatória. Segurança do paciente. Erros médicos.

ABSTRACT: Objective: To identify the occurrence of serious adverse events (SAE) in surgical patients and their possible outcomes. Method: Retrospective quantitative study, performed by the analysis of records and data of perioperative patients, who suffered SAE in 2016 at a private hospital in São Paulo. Results: There were 19 SAEs, mostly in female patients aged 40 to 49 years, hospitalized by gastroenterological pathologies. The most frequent occurrences were damage in digestive organs, hemorrhagic shock and vascular lesion. Regarding outcomes, patients were referred to the intensive therapy unit, medical-surgical clinic and hemodynamics; two patients died. Conclusion: The nursing staff should be aware of factors that may lead to SAE and receive guidance on notification, so they can improve surgical patients' safety and care.

Keywords: Perioperative nursing. Patient safety. Medical errors.

RESUMEN: Objetivo: Identificar la ocurrencia de eventos adversos graves (EAG) en pacientes quirúrgicos y sus posibles desenlaces. Método: Estudio retrospectivo, cuantitativo, realizado por el análisis de prontuarios y banco de datos de pacientes en el perioperatorio, que sufrieron EAG en 2016, en un hospital privado de São Paulo. Resultados: Ocurrieron 19 EAG, con predominancia de pacientes del sexo femenino, entre 40 y 49 años, internados por patologías del sistema gastroenterológico. Las ocurrencias más incidentes fueron: lesión de órganos digestivos, choque hemorrágico y lesión vascular. Cuanto a los desenlaces, los pacientes fueron encaminados a la unidad de terapia intensiva, clínica médico-quirúrgica y hemodinámica; dos pacientes evolucionaron a óbito. Conclusión: Los profesionales del equipo de enfermería deben estar atentos a los factores que pueden contribuir para la ocurrencia de EAG y orientados con relación a la notificación, a fin de perfeccionar la seguridad y la calidad de la asistencia prestada a los pacientes quirúrgicos. Palabras clave: Enfermería perioperatoria. Seguridad del paciente. Errores médicos.

'Enfermeira pela Faculdade Israelita de Ciências da Saúde Albert Einstein - São Paulo (SP), Brasil.

2Enfermeira; especialista em Cardiologia e Centro Cirúrgico; mestre e doutora em Enfermagem; professora da Faculdade Israelita de Ciências da Saúde Albert Einstein - São Paulo (SP), Brasil.

*Autor correspondente: rachel.carvalho@einstein.br

Recebido: 19/12/2017 - Aprovado: 03/03/2018

DOI: $10.5327 / 21414-4425201800020004$ 


\section{INTRODUÇÃO}

Estima-se que 234 milhões de procedimentos cirúrgicos de maior complexidade sejam realizados por ano. À proporção que as incidências de injúrias traumáticas, cânceres e doenças cardiovasculares continuam a subir, as intervenções cirúrgicas tendem a crescer ${ }^{1}$.

A Organização Mundial da Saúde lançou, em 2004, a Aliança Mundial para Segurança do Paciente, tendo como objetivo adotar medidas de melhoria no atendimento ao paciente e amplificar a qualidade dos serviços de saúde ${ }^{1}$.

O procedimento cirúrgico é o único tratamento que tem a finalidade de amenizar as incapacidades e diminuir o risco de morte causada por enfermidades. Apesar de salvar inúmeras vidas, a falta de acesso à cirurgia de qualidade é considerada um problema em grande parte do mundo ${ }^{1}$.

São registradas sete milhões de complicações cirúrgicas a cada ano, abrangendo, no mínimo, um milhão de pacientes que evoluem a óbito, durante ou imediatamente depois do procedimento cirúrgico ${ }^{1}$.

Nos últimos tempos, a segurança do paciente vem se tornando uma preocupação constante para o setor da saúde, por ser um princípio fundamental, ao prestar os cuidados necessários a cada indivíduo. A falha na segurança durante a assistência pode causar danos consideráveis ao paciente. Essa questão vem sendo debatida devido ao impacto que os eventos adversos trazem para os sistemas de saúde ${ }^{2}$.

Eventos adversos graves (EAG) são definidos como incidentes que ocorrem durante a assistência prestada ao longo da internação do paciente, podendo resultar em infecção de sítio cirúrgico, posicionamento cirúrgico inadequado, procedimento em lado errado do corpo, administração incorreta de medicamentos e problemas no ato anestésico-cirúrgico. Tais eventos prolongam a permanência no hospital, elevam o custo da internação e, nos casos mais graves, há risco de óbito 3 .

Os eventos adversos relacionados aos procedimentos cirúrgicos merecem atenção especial, pois o Centro Cirúrgico (CC) é o local onde eles ocorrem com maior frequência. Trata-se de uma das unidades mais complexas do hospital, em razão da intensa circulação de profissionais de diversas áreas da saúde e da diversidade dos procedimentos anestésico-cirúrgicos e diagnósticos. Estima-se que 50\% dos EAG estejam relacionados à assistência cirúrgica e que poderiam ter sido evitados ${ }^{1,3}$.

A partir do momento que o evento adverso ocorre, é preciso que seja notificado. A notificação desses eventos passou a ser um importante instrumento para o aperfeiçoamento da qualidade do sistema de saúde. O sistema de notificação equivale às ações interligadas para verificar e averiguar os EAG, no intuito de aprimorar a segurança do paciente durante a sua internação ${ }^{4}$.

Entretanto, alguns eventos não são notificados pela equipe de enfermagem. Essas subnotificações estão constantemente relacionadas à falta de compreensão sobre a importância e os procedimentos necessários para a notificação, além do receio dos profissionais em ter seus nomes e identidades comprometidas, com medo de punições, sejam elas verbais ou escritas. Diante desse fato, a subnotificação pode camuflar a totalidade dos eventos adversos ${ }^{5}$.

Para obter o sucesso do tratamento cirúrgico, é necessário implantar uma assistência individualizada e de forma integral, específica em todos os momentos do período perioperatório. O propósito é possibilitar ao paciente uma recuperação mais eficaz e rápida, isto é, uma assistência de qualidade. A segurança do paciente é dever de todos os profissionais da saúde, inclusive da equipe de enfermagem, que tem papel primordial na prevenção da ocorrência dos $\mathrm{EAG}^{3}$.

A equipe de enfermagem é responsável pelo preparo do paciente, desenvolvendo e estabelecendo cuidados específicos para cada tipo de cirurgia e planejados de acordo com a individualidade de cada paciente. Cuidados esses que incluem orientação adequada sobre o procedimento a ser realizado, preparo físico e emocional, administração de pré-anestésico, quando prescrito, e encaminhamento do paciente até o CC, dentre tantas outras atribuições ${ }^{6}$.

Diante desse cenário, é de extrema importância reconhecer os EAG e verificar o desfecho para os pacientes, vítimas de tais eventos.

\section{OBJETIVO}

Identificar a ocorrência de eventos adversos graves no período perioperatório e o desfecho dos mesmos, junto a pacientes cirúrgicos.

\section{MÉTODO}

Trata-se de uma pesquisa documental, retrospectiva, descritivo-exploratória, com análise quantitativa, realizada por meio de documentação primária, em prontuários de pacientes e em banco de dados de pacientes cirúrgicos que estiveram internados em um hospital de porte extra, da rede privada, situado na zona sul de São Paulo. A instituição possui 728 leitos ativos e realiza, em média, 3 mil procedimentos anestésico-cirúrgicos por mês. 
A amostra do estudo foi composta pelos prontuários e registros em banco de dados de 19 pacientes que sofreram EAG, durante o perioperatório, no ano de 2016. Considerando-se uma média de 3 mil cirurgias por mês, a ocorrência de EAG foi de $0,053 \%$ no período de 1 ano, na instituição sede do estudo.

A coleta das informações nos prontuários e no banco de dados dos pacientes foi realizada no primeiro semestre de 2017, mediante o preenchimento de formulário, especificamente elaborado pelas autoras para o presente estudo, contendo 14 itens, organizados em 3 partes:

- Parte I: caracterização da amostra (sexo, idade, patologia principal);

- Parte II: informações sobre o procedimento anestésico-cirúrgico (anestesia realizada, duração da anestesia, cirurgia realizada, classificação da cirurgia quanto ao potencial de contaminação, duração da cirurgia e tempo de internação);

- Parte III: informações sobre o EAG (local da ocorrência/notificação, tipo de EAG, desfecho após a ocorrência do EAG e intervenções frente ao EAG).

Os dados foram coletados após aprovação do projeto de pesquisa pelo Comitê de Ética em Pesquisa (CEP) da instituição via Plataforma Brasil (CAAE 62113016.9.0000.0071). Pelo fato da amostra ter sido composta por prontuários de pacientes e banco de dados, pediu-se autorização ao coordenador do CEP da instituição para não utilização do Termo de Consentimento Livre e Esclarecido (TCLE) e a mesma foi concedida. As pesquisadoras se comprometem a manter o sigilo das informações obtidas e a utilizar os dados somente para o presente estudo.

Os resultados foram analisados a partir de estatística descritiva quantitativa, segundo média e porcentagens, e são demonstrados em números absolutos e percentuais, por meio de tabelas e gráfico, no intuito de facilitar e organizar os dados.

Para aquisição dos resultados da caracterização dos pacientes, cada linear da amostra foi dividida conforme descrito e, dessa forma, possibilitou o cálculo da média de cada item: sexo, subdividido em feminino e masculino; idade, com as subdivisões em intervalos de dez anos; e patologia principal, subdivida em cardiovascular, estética, gastroenterológica, ginecológica, musculoesquelética, neoplasia, pulmonar e respiratória.

Para aquisição dos resultados foram delimitadas as seguintes ocorrências: abordagem cirúrgica desnecessária, bloqueio anestésico realizado no membro errado, cateter alocado em lugar inadequado, choque hemorrágico, corpo estranho em orofaringe, lesão de órgãos digestórios, lesão de órgãos urinários, lesão vascular, parada cardiorrespiratória (PCR), queimadura por bisturi elétrico, sangramento após revascularização do miocárdio (RM) e síndrome compartimental.

Para obtenção dos resultados do desfecho dos EAG foram definidas as áreas de: clínica médico-cirúrgica, clínica pediátrica, hemodinâmica, óbito, quadro infeccioso e unidade de terapia intensiva(UTI).

Foram computados outros dados, como: anestesia realizada, duração da anestesia, classificação da cirurgia (eletiva, urgência e emergência), classificação da cirurgia quanto ao potencial de contaminação (limpa, potencialmente contaminada, contaminada e infectada), cirurgia realizada, duração da cirurgia e tempo de internação.

\section{RESULTADOS}

\section{Caracterização da amostra}

A Tabela 1 apresenta os dados da caracterização da amostra, composta dos 19 pacientes que sofreram EAG, no ano de 2016, na instituição sede da pesquisa.

Tabela 1. Características da amostra dos pacientes que sofreram eventos adversos graves.

\begin{tabular}{|l|c|c|}
\hline Variável/Categoria & $\mathbf{n}$ & $\%$ \\
\hline Sexo & 11 & 57,89 \\
\hline Feminino & 08 & 42,11 \\
\hline $\begin{array}{l}\text { Masculino } \\
\text { Faixa etária (anos) }\end{array}$ & 01 & 5,26 \\
\hline 0 a 9 & 01 & 5,26 \\
\hline 10 a 19 & - & - \\
\hline 20 a 29 & 02 & 10,53 \\
\hline 30 a 39 & 05 & 26,32 \\
\hline 40 a 49 & 04 & 21,05 \\
\hline 50 a 59 & 02 & 10,53 \\
\hline 60 a 69 & 03 & 15,79 \\
\hline 70 a 79 & 01 & 5,26 \\
\hline 80 a 89 & & \\
\hline Patologia principal & 07 & 36,84 \\
\hline Gastroenterológico & 04 & 21,05 \\
\hline Cardiovascular & 02 & 10,53 \\
\hline Musculoesquelético & 02 & 10,53 \\
\hline Neoplasia & 01 & 5,26 \\
\hline Estética & 01 & 5,26 \\
\hline Ginecológico & 01 & 5,26 \\
\hline Pulmonar & 01 & 5,26 \\
\hline Respiratório & 19 & 100,00 \\
\hline Total & & \\
\hline
\end{tabular}


Entre os 19 pacientes, 11 (57,89\%) são do sexo feminino, em sua maioria com idade entre 40 e 49 anos ( $n=05 ; 26,32 \%$ ) e entre 50 e 59 anos $(n=04 ; 21,05 \%)$. Sete pacientes $(36,84 \%)$ internaram com patologia principal do sistema gastroenterológico, sendo elas: colecistite aguda, suboclusão intestinal, endometriose intestinal, fístula entérica, hérnia inguinal e doença do refluxo gastroesofágico (Tabela 1).

\section{Informações sobre 0 procedimento anestésico-cirúrgico}

A Tabela 2 apresenta os dados referentes ao procedimento anestésico-cirúrgico dos 19 pacientes que foram submetidos à cirurgia e sofreram EAG.

Dos 19 pacientes que compuseram a amostra, $16(84,21 \%)$ realizaram o procedimento cirúrgico sob anestesia geral, 10 (52,63\%) cirurgias foram de urgência e 11 (57,89\%), classificadas como cirurgias limpas, segundo o potencial de contaminação (Tabela 2).

\section{Ocorrência e desfecho após 0 evento adverso grave}

Com a finalidade de verificar a ocorrência e o desfecho dos EAG dos pacientes da amostra, verificou-se, também, o tipo do EAG (Tabela 3).

Os eventos adversos que mais ocorreram nos 19 pacientes da amostra foram: 4 (21,05\%) lesões de órgãos digestórios, 2 pacientes (10,53\%) tiveram choque hemorrágico e 2 (10,53\%) apresentaram lesões vasculares (Tabela 3).

Tabela 2. Informações sobre o procedimento anestésico-cirúrgico.

\begin{tabular}{|l|c|c|}
\hline Variável/Categoria & $\mathbf{n}$ & $\%$ \\
\hline Anestesia realizada & 16 & 84,21 \\
\hline Geral & 01 & 5,26 \\
\hline Local & 01 & 5,26 \\
\hline Raquianestesia & 01 & 5,26 \\
\hline Raquianestesia + sedação & & \\
\hline Classificação da cirurgia & 10 & 52,63 \\
\hline Urgência & 06 & 31,58 \\
\hline Eletiva & 03 & 15,79 \\
\hline Emergência & 11 & 57,89 \\
\hline Classificação da cirurgia quanto ao potencial de contaminação \\
\hline Limpa & 06 & 31,58 \\
\hline Potencialmente contaminada & 01 & 5,26 \\
\hline Contaminada & 01 & 5,26 \\
\hline Infectada & 19 & 100,00 \\
\hline Total
\end{tabular}

Os principais desfechos após as ocorrências dos EAG estão apresentados na forma de gráfico (Figura 1), sendo que 8 pacientes $(42,11 \%)$ foram transferidos para a UTI, 5 (26,32\%) permaneceram internados na clínica médico-cirúrgica, 2 (5,26\%) foram encaminhados à hemodinâmica e 2 (5,26\%) evoluíram a óbito.

Tabela 3. Características das ocorrências dos eventos adversos graves.

\begin{tabular}{|l|l|c|}
\hline Eventos adversos graves & $\mathbf{n}$ & $\%$ \\
\hline Lesão de órgãos digestórios & 04 & 21,05 \\
\hline Lesão vascular & 02 & 10,53 \\
\hline Choque hemorrágico & 02 & 10,53 \\
\hline Cateter alocado em local inadequado & 01 & 5,26 \\
\hline Bloqueio anestésico realizado no membro errado & 01 & 5,26 \\
\hline Corpo estranho em orofaringe & 01 & 5,26 \\
\hline Abordagem cirúrgica desnecessária & 01 & 5,26 \\
\hline Lesão de órgãos urinários & 01 & 5,26 \\
\hline Parada cardiorrespiratória & 01 & 5,26 \\
\hline Queimadura por bisturi elétrico & 01 & 5,26 \\
\hline Sangramento após revascularização do miocárdio & 01 & 5,26 \\
\hline Síndrome compartimental & 01 & 5,26 \\
\hline Uso de material não estéril na cirurgia & 01 & 5,26 \\
\hline Divergência na contagem de compressas & 01 & 5,26 \\
\hline Total & 19 & 100,00 \\
\hline
\end{tabular}
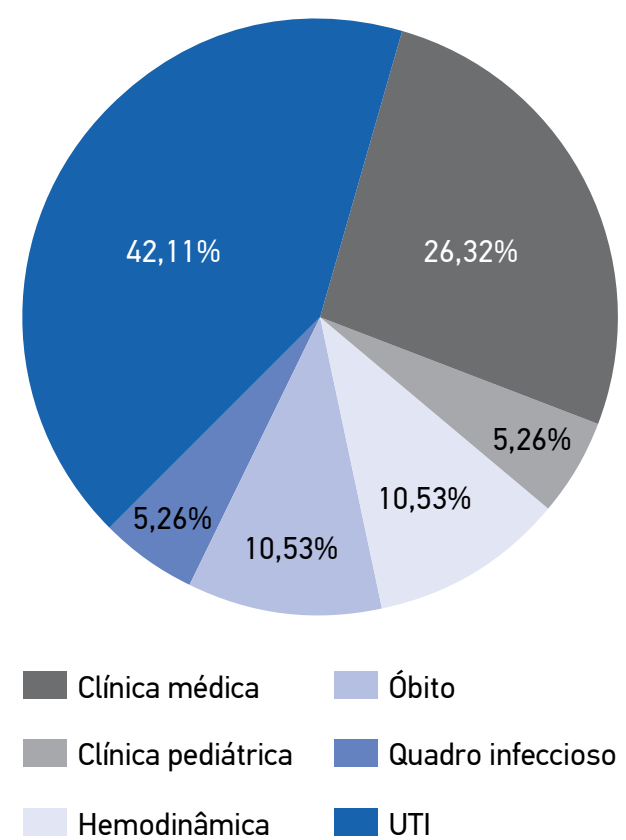

Figura 1. Desfecho após a ocorrência do evento adverso grave. 


\section{DISCUSSÃO}

A assistência de enfermagem ao paciente cirúrgico, em qualquer uma das etapas operatórias, provoca uma série de ações, as quais a equipe deve atentar para manter a segurança do paciente ${ }^{7}$.

No hospital, o CC é um ambiente onde ocorre grande parte dos eventos adversos. Muitos fatores contribuem para as causas, devido à alta complexidade dos procedimentos ${ }^{8}$.

No presente estudo, foram evidenciados 4 EAG $(21,05 \%)$ relacionados à lesão de órgãos digestórios durante cirurgias videolaparoscópicas, como jejuno, fígado e estômago, sendo que a lesão do jejuno trouxe um impacto importante à vida do paciente, causando aumento do tempo de internação e sendo necessária a realização de ileostomia. O uso de diferentes instrumentos para a realização de cirurgias laparoscópicas, na cavidade abdominal, pode ocasionar perfuração de alguns órgãos. A maioria das complicações decorrentes do acesso à cavidade ocorre pela realização de manobras sem a visualização direta do cirurgião?

Outros 2 EAG (10,53\%) que ocorreram foram relacionados com a cirurgia realizada para correção de aneurisma da aorta abdominal, e ambos os pacientes evoluíram a óbito, devido à lesão de artérias ilíacas e isquemia mesentérica. A cirurgia endovascular para a correção do aneurisma da aorta abdominal não está livre de complicações, que podem ocorrer durante ou após o procedimento. $\mathrm{O}$ aumento da morbimortalidade dos pacientes que realizaram esse tipo de cirurgia não está definida; e não se sabe, ainda, se está ou não relacionada à técnica cirúrgica ${ }^{10}$.

Neste estudo aconteceram 2 EAG $(10,53 \%)$ relacionados ao choque hemorrágico, sendo que um deles se deu durante o procedimento cirúrgico de RM, onde houve a desconexão acidental do circuito de circulação extracorpórea (CEC), com perda de sangue significativa. Algumas complicações podem ocorrer durante ou após a cirurgia e uma delas é a hemorragia, que apresenta como fatores etiológicos a ruptura de alguma ligadura ou hemostasia realizada de forma ineficiente. A consequência clínica depende do calibre do vaso, do tipo de sangramento e da quantidade de sangue perdido numa fração de tempo. A hipovolemia coloca em risco a vida do paciente e necessita de diagnóstico precoce e de hemostasia definitiva, frequentemente realizada em uma nova intervenção cirúrgica (reoperação) ${ }^{11}$.

Em referência à presente pesquisa, ocorreu um evento onde a paciente foi realizar uma cirurgia eletiva estética e sofreu queimadura de grau II pelo bisturi elétrico (BE). Um estudo feito em uma escola pública do Ceará, com 40 profissionais da área da saúde, entre médicos e enfermeiros, com a finalidade de avaliar os incidentes com BE no CC, teve como resultado a falta de familiarização com o equipamento ou de manutenção, que era realizada apenas quando ocorria defeito ${ }^{12}$.

Ocorreu um EAG onde o paciente foi ao CC para passagem de cateter venoso central (CVC) e, após a passagem, evoluiu com sonolência e perda de força motora à esquerda. Foram feitos alguns exames, como raio $\mathrm{X} \mathrm{e}$ angiotomografia, que evidenciaram que o cateter estava alocado em local inadequado. $\mathrm{O}$ acesso venoso central é frequentemente utilizado para monitoração, infusão de fluidos e fármacos vasoativos. Apesar dos benefícios, sua obtenção envolve riscos, como arritmias, coleção de líquido mediastinal, hemotórax, perfuração das câmaras cardíacas e tamponamento cardíaco ${ }^{13,14}$.

No presente estudo, foi evidenciado um caso onde a contagem de compressas não foi feita de modo eficaz, acarretando, assim, em uma nova abordagem cirúrgica e nessa abordagem foi localizada a compressa na cavidade abdominal do paciente. Para certificar a prevenção de retenção de objetos ou corpos estranhos intracavitários durante o período intraoperatório, o processo de contagem cirúrgica é recomendado em todas as cirurgias. A contagem é um processo manual, de responsabilidade do enfermeiro assistencial, do técnico de enfermagem, atuando como circulante de sala, juntamente com o instrumentador ${ }^{15}$.

No estudo realizado, houve uma parada cardiorrespiratória $(\mathrm{PCR})$ durante um procedimento cirúrgico, no qual a equipe abordava um tumor cerebral. Nesse caso, a paciente, uma criança, foi reestabilizada hemodinamicamente e encaminhada à UTI pediátrica. A Revista Brasileira de Anestesiologia publicou um levantamento onde a incidência de PCR no intraoperatório variou de 2,56 a 44 casos por 10 mil procedimentos. A PCR é o evento adverso mais grave, potencialmente reversível, que pode ocorrer durante a realização de uma cirurgia ${ }^{16}$.

No presente estudo, foi evidenciado que no pós-operatório de segmentectomia pulmonar e adrenalectomia, com duração de 10 horas, o paciente evoluiu com síndrome compartimental (SC), necessitando de reabordagem cirúrgica para realização de fasciotomia. A SC, apesar de ser mais frequentemente associada a traumas, tem sido relatada como consequência do posicionamento nas mesas de operação durante cirurgias prolongadas, que foi 
o caso relatado. A SC intraoperatória causada por posicionamento prolongado tem início sutil; e a ausência de achados sintomáticos, enquanto o paciente está anestesiado, faz com que ela se torne uma complicação que pode facilmente passar despercebida no intra e no pós-operatório ${ }^{17}$. No entanto, um estudo analisado reportou a ocorrência dessa complicação após cirurgias de média duração, entre 3 e 4 horas ${ }^{18}$.

No atual estudo, o paciente que fez a RM teve que voltar para o CC (reoperação) após o primeiro dia de pós-operatório devido à ocorrência de sangramento importante. Em um estudo feito num hospital geral no município de Cascavel, Paraná, com 119 pacientes que foram submetidos à cirurgia de RM, 28 (23,5\%) apresentaram complicações no período pós-operatório ${ }^{19}$.

Houve um evento no qual a paciente foi submetida à histerectomia e salpingectomia e no segundo dia de pós-operatório evoluiu com aumento do débito do dreno, sendo coletada amostra de creatinina do material, com resultado positivo. Houve necessidade de retornar ao CC (reoperação) para realizar laparotomia exploradora e rafia/sutura da bexiga. A lesão vesical é a complicação mais comum da histerectomia vaginal, sendo sua incidência calculada entre 0,4 e 1,86\%. A parede posterior da bexiga é, geralmente, a mais lesada, seja por desvascularização ou laceração ${ }^{20}$.

Outros eventos ocorreram durante o procedimento cirúrgico, dentre eles o bloqueio anestésico realizado no membro errado, gaze na orofaringe, abordagem cirúrgica desnecessária e utilização de material não estéril. Apesar de serem considerados EAG, esses eventos não trouxeram maiores danos ou prolongamento da internação dos pacientes.

Após a ocorrência dos EAG, os pacientes foram encaminhados para diferentes setores, de acordo com o quadro clínico que cada um apresentava. Entre os 19 pacientes que compuseram a amostra, $8(42,11 \%)$ foram transferidos para a UTI, devido à instabilidade hemodinâmica; 5 $(26,32 \%)$ foram conduzidos até a clínica médico-cirúrgica para dar continuidade ao tratamento; $2(5,26 \%)$ foram encaminhados à hemodinâmica, setor onde é realizado um rápido diagnóstico e no qual o início do tratamento muitas vezes é um fator fundamental para a sobrevivência do paciente; e $2(5,26 \%)$ pacientes evoluíram para óbito, 1 por isquemia mesentérica e 1 por ausência de fluxo de artérias ilíacas bilaterais.

Referente às informações do procedimento anestésicocirúrgico, 16 (84,21\%) pacientes realizaram o procedimento sob anestesia geral. O tempo médio da duração da anestesia, do total da amostra, foi de 3 horas e 48 minutos, sendo o maior tempo de 8 horas e 45 minutos e o menor tempo, de 50 minutos.

De acordo com a urgência dos procedimentos cirúrgicos, os mesmos são classificados em: urgência, emergência e eletiva ${ }^{21}$. No presente estudo, ocorreram $10(52,63 \%)$ cirurgias de urgência, $6(31,58 \%)$ eletivas e $3(15,79 \%)$ de emergência. O tempo médio de duração da cirurgia foi de 3 horas e 57 minutos, sendo o maior tempo de 8 horas e 15 minutos e o menor tempo, de 30 minutos.

Conforme o potencial de contaminação, as cirurgias são classificadas em: limpa, potencialmente contaminada, contaminada e infectada ${ }^{21}$. Dos 19 pacientes da amostra, $11(57,89 \%)$ cirurgias foram classificadas como limpas, 6 $(31,58 \%)$ como potencialmente contaminadas, $1(5,26 \%)$ como contaminada e $1(5,26 \%)$ como infectada.

O tempo de permanência dos pacientes no hospital foi, em média, 10,6 dias, sendo o maior tempo de internação de 43 dias e o menor, de 1 dia. Segundo a Agência Nacional de Saúde Suplementar (ANS), o tempo de internação ideal para hospitais de grande porte oscila entre 4 e 5 dias de permanência ${ }^{22}$.

\section{CONCLUSÃO}

Este estudo permitiu concluir que, entre os 19 pacientes que compuseram a amostra, houve predominância do sexo feminino, com idades entre 40 e 49 anos e patologia principal de internação relacionada com o sistema gastroenterológico.

As ocorrências dos EAG que mais predominaram foram as lesões de órgãos digestórios, seguidas de choque hemorrágico e lesão vascular. Em relação ao desfecho após as ocorrências, os pacientes foram encaminhados à UTI, clínica médico-cirúrgica, hemodinâmica e dois evoluíram a óbito.

Por ser um ambiente de alta complexidade e alta rotatividade, toda a equipe deve estar atenta aos fatores que podem prejudicar a segurança do paciente, individualizando, assim, a assistência prestada a cada paciente cirúrgico.

O número de eventos encontrados durante a pesquisa foi baixo $(0,053 \%)$, quando comparado à alta demanda e rotatividade do CC (cerca de 3 mil procedimentos por mês). Mesmo assim, a instituição sede desta pesquisa busca implementar constantes estratégias de melhoria e notificação, para que os EAG sejam cada vez mais escassos. 


\section{REFERÊNCIAS}

1. Brasil. Organização Mundial da Saúde. Cirurgias seguras salvam vidas: segundo desafio global para a segurança do paciente: Manual - cirurgias seguras salvam vidas [Internet]. Rio de Janeiro: ANVISA; 2009 [citado 17 set. 2016]. Disponível em: http://bvsms.saude.gov.br/ bvs/publicacoes/seguranca_paciente_cirurgias_seguras_guia.pdf

2. Souza LP, Bezerra ALQ, Camargo e Silva AEB, Carneiro FS, Paranaguá TTB, Lemos LF. Eventos adversos: instrumento de avaliação do desempenho em centro cirúrgico de um hospital universitário. Rev Enf UERJ. 2011;19(1):127-33.

3. Bohomol E, Tartali JA. Eventos adversos em pacientes cirúrgicos: conhecimento dos profissionais de enfermagem. Acta Paul Enferm. 2013;26(4):376-81. http://dx.doi.org/10.1590/ S0103-21002013000400012

4. de Paiva MCMS, Popim RC, Melleiro MM, Tronchim DMR, Lima SAM, Juliani CMCM. Motivos da equipe de enfermagem para notificação de eventos adversos. Rev Latino-Am Enferm. 2014;22(5):747-54. DOI: 10.1590/0104-1169.3556.2476

5. Waldman EA. Usos da vigilância e da monitorização em saúde pública. IESUS [Internet]. 1998 [citado 18 set. 2016];7(3):8-26. Disponível em: http://scielo.iec.pa.gov.br/pdf/iesus/v7n3/v7n3a02.pdf

6. Cristóforo BEB, Carvalho DS. Cuidados de enfermagem realizados ao paciente cirúrgico no período pré-operatório. Rev Esc Enferm USP. 2009;43(1):14-22. http://dx.doi.org/10.1590/ S0080-62342009000100002

7. Lima AM, Sousa CS, da Cunha ALSM. Segurança do paciente e montagem de sala operatória: estudo de reflexão. Rev Enferm UFPE. 2013;7(1):289-94. DOI: 10.5205/reuol.3049-24704-1-LE.0701201337

8. Secanell M, Orrego C, Vila M, Vallverdú H, Mora N, Oller A, et al. A surgical safety checklist implementation: experience of a start-up phase of a collaborative project in hospitals of Catalonia, Spain. Med Clin (Barc). 2014;143(Suppl. 1):17-24. https://doi.org/10.1016/j. medcli.2014.07.007

9. Campos FGCM, Roll S. Complicações do acesso abdominal e do pneumoperitônio em cirurgia laparoscópica - causas, prevenção e tratamento. Rev Bras Videocir. 2003;1(1):21-8.

10. Ribeiro ALC, Pereira ER, Farias MSQ, Pontes SMM, de Vasconcelos TB, Bastos VPD. Morbi-mortalidade em cirurgia de correção de aneurisma de aorta em um hospital público de Fortaleza-CE: estudo retrospectivo. Saúde Santa Maria. 2015;41(1):111-6.

11. Stracieri LDS. Cuidados e complicações pós-operatórias. Medicina (Ribeirão Preto) [Internet]. 2008 [citado 09 nov. 2017]; 41(4):4658. Disponível em: https://www.revistas.usp.br/rmrp/article/ viewFile/288/289

12. Cabral LAL. Avaliação de acidentes com bisturi elétrico no centro cirúrgico de um estabelecimento assistencial de saúde pública no município de Fortaleza, Ceará [trabalho de conclusão de curso]. Fortaleza: Escola de Saúde Pública do Ceará; 2008.

13. Pelicano JF, Abrantes RCG, Pegoraro FA, Amorim ERB, Lima Júnior JA. Complicação de acesso venoso central: hidrotórax. Med J [Internet]. 2005 [citado 05 nov. 2017];123(Suppl.):25. Disponível em: http://www.scielo.br/pdf/spmj/v123sspe/v123s1a20.pdf

14. Búrigo CCP. Posicionamento do cateter venoso a central em pacientes de UTI: um estudo prospectivo [trabalho de conclusão de curso]. Florianópolis: Universidade Federal de Santa Catarina; 1995 [citado 08 nov. 2017]. Disponível em: https://repositorio.ufsc.br/bitstream/ handle/123456789/113407/253040.pdf?sequence=1

15. Freitas PS, Mendes KDS, Galvão CM. Processo de contagem cirúrgica: evidências para a segurança do paciente. Rev Gaúcha Enferm. 2016;37(4):1-8. http://dx.doi.org/10.1590/1983-1447.2016.04.66877

16. Vane MF, Nuzzi RXP, Aranha GF, da Luz VF, Malbouisson LMS, Gonzalez MMC, et al. Parada cardíaca perioperatória: uma análise evolutiva da incidência de parada cardíaca intraoperatória em centros terciários no Brasil. Rev Bras Anestesiol [Internet]. 2016 [citado 08 nov. 2017];66(2):17682. Disponivel em: http://www.scielo.br/pdf/rba/v66n2/pt_1806-907Xrba-66-02-00176.pdf. https://doi.org/10.1016/j.bjan.2016.01.001

17. Sérgio FR, Cameron LE, Vital ICO. Síndrome compartimental relacionada ao posicionamento cirúrgico: um inimigo silencioso. Rev SOBECC. 2012;17(3):71-80.

18. de Godoy JMP, de Godoy MF, da Silva AM, Reis LF. Síndrome compartimental e minifasciotomia diagnóstica. Cir Vasc Angiol [Internet]. 1998 [citado 05 nov. 2017];14:99-102. Disponível em: http:// jvascbras.com.br/revistas-antigas/1998/3/02/1998_a14_n3-2.pdf

19. Carvalho ARS, Matsuda LM, Carvalho MSS, de Almeida RMSSA, Schneider DSLG. Complicações no pós-operatório de revascularização miocárdica. Maringá [Internet]. 2006 [citado 09 nov. 2017];5(1):50-9. Disponivel em: http://eduem.uem.br/ojs/index.php/CiencCuidSaude/ article/viewFile/5111/3326

20. Barboza LMS. Histerectomia vaginal: uma revisão sobre complicações e métodos profiláticos [trabalho de conclusão de curso]. Goiás: Pontifícia Universidade Católica. [citado 09 nov. 2017]. Disponível em: http://www.cpgls.pucgoias.edu.br/6mostra/artigos/SAUDE/ L\%C3\%8DDIA\%20MARTINS\%20SPADONI\%20BARBOSA\%20E\%20 RUI\%20GILBERTO\%20FERREIRA.pdf

21. de Carvalho R, de Moraes MW. Inserção do centro cirúrgico no contexto hospitalar. In: de Carvalho R, Bianchi ERF, eds. Enfermagem em centro cirúrgico e recuperação. 2a ed. Barueri: Manole; 2016. p.118. Capítulo 1.

22. Brasil. Ministério da Saúde. Agência Nacional de Saúde Suplementar. Média de permanência geral [Internet]. Rio de Janeiro: ANS; 2013 [citado 20 nov. 2017]. Disponível em: http://www.ans.gov.br/images/ stories/prestadores/E-EFI-05.pdf 